\title{
Treatment of paroxysmal supraventricular tachycardia with intravenous injection of adenosine triphosphate
}

\author{
DAIJI SAITO, MASAYUKI UEEDA, YUKIHIRO ABE, HIDEKI TANI, \\ TAKAAKI NAKATSU, HIDENORI YOSHIDA, SHOICHI HARAOKA, \\ HIDEO NAGASHIMA \\ From the First Department of Internal Medicine, Okayama University Medical School, Okayama, fapan
}

SUMMARY Intravenous adenosine triphosphate rapidly terminated all 11 episodes of paroxysmal supraventricular tachycardia in 10 patients. Eight patients reported side effects but these resolved within 20 seconds and did not require treatment.

Adenosine triphosphate is a suitable agent for the rapid termination of paroxysmal supraventricular tachycardia.

Verapamil, propranolol, digitalis, and cardioversion have all been used to treat paroxysmal supraventricular tachycardia. Since 1955 adenosine triphosphate has also been used in some parts of Europe to treat acute episodes of paroxysmal supraventricular tachycardia, and the electrophysiological effects of this agent have been reviewed by Belhassen and Pelleg. ${ }^{1}$ The effect of adenosine triphosphate on the sinus and atrioventricular nodes has been investigated in animals. ${ }^{23}$ The effects of adenosine triphosphate are largely mediated by its metabolite, adenosine. Adenosine, which is increased in the ischaemic myocardium, has been implicated in the causation of atrioventricular block. ${ }^{45}$ DiMarco et al reported that intravenous adenosine depressed sinus node automaticity and atrioventricular conduction and was an effective agent in the treatment of reentrant supraventricular arrhythmias. ${ }^{6}$ More recently the effect of adenosine on atrioventricular conduction has been attributed to its binding to extracellular receptors. ${ }^{7}$ Adenosine, like acetylcholine, has been reported to increase potassium conductance, $^{8}$ to reduce calcium mediated slow channel influx, ${ }^{9}$ and possibly to have indirect antiadrenergic effects. ${ }^{10}$ Adenosine triphosphate in dogs had direct negative dromotropic and chronotropic effects (not involving a cholinergic component)

Requests for reprints to Dr Daiji Saito, The First Department of Internal Medicine, Okayama University Medical School, 2-5-1 Shikata-cho, Okayama 700, Japan.

Accepted for publication 30 September 1985 which lasted for 5-30 seconds, and repeated administration produced neither tolerance nor cumulative effects. ${ }^{3}$ The purpose of the present study was to determine the efficacy, rapidity of action, and side effects of adenosine triphosphate in the treatment of paroxysmal supraventricular tachycardia.

\section{Patients and methods}

We studied 11 episodes of tachycardia in 10 patients (6 men and 4 women, mean (SD) age 56 (15) years). Table 1 shows the clinical characteristics of the patients. Five patients had been treated over several years at intervals of 1-9 months. One patient (case 4) had sick sinus syndrome with bradycardiatachycardia syndrome. Another had isolated Wolff-Parkinson-White syndrome, and none had congestive heart failure. During the episodes of tachycardia all patients complained of palpitation, two complained of mild dyspnoea, and two complained of cold sweats.

\section{FEATURES OF TACHYCARDIA}

The heart rate ranged from 146 to 200 beats per minute, and in each patient the rate was constant from minute to minute. The $P$ wave was not seen in $8(73 \%)$ episodes; it apparently occurred simultaneously with the $Q R S$ complex. The $P$ wave was confined to the proximal portion of the ST segment in two patients so that the $\mathbf{R}-\mathbf{P}^{\prime}$ interval was shorter than the $P^{\prime}-R$ interval. One patient (case 3 ) had longer $R-P^{\prime}$ intervals than $P^{\prime}-R$ intervals, suggesting a fast-slow form of junctional re-entrant tachy- 
Table 1 Clinical characteristics of patients with paroxysmal supraventricular tachycardia

\begin{tabular}{|c|c|c|c|c|c|}
\hline & \multirow[t]{2}{*}{ Age (yr) } & \multirow{2}{*}{$\begin{array}{l}\text { Heart rate } \\
\text { (beat } / \text { min) }\end{array}$} & \multicolumn{2}{|c|}{ Blood pressure (kPa) } & \multirow{2}{*}{$\begin{array}{l}\text { Interval from beginning of } \\
\text { attack to treatment }(h)\end{array}$} \\
\hline & & & Systole & Diastole & \\
\hline $\begin{array}{l}\text { Mean } \\
\text { Range }\end{array}$ & $\begin{array}{l}56 \\
28-76\end{array}$ & $\begin{array}{l}168 \\
146-200\end{array}$ & $\begin{array}{l}12 \cdot 57 \\
7 \cdot 71-15 \cdot 96\end{array}$ & $\begin{array}{l}\text { NA } \\
\text { Undetectably law- } \\
\quad 13 \cdot 30\end{array}$ & $\begin{array}{l}2 \cdot 6 \\
0 \cdot 2-5 \cdot 0\end{array}$ \\
\hline
\end{tabular}

Because diastolic blood pressure was undetectably low in four episodes, mean values of diastolic pressure were not calculated.

Conversion: SI to traditional units $-1 \mathrm{kPa}=7.5 \mathrm{~mm} \mathrm{Hg}$.

cardia. ${ }^{11}$ The QRS configuration was identical to that of sinus rhythm except in the patient with Wolff-Parkinson-White syndrome in whom the duration of the QRS complex was normal during tachycardia.

\section{STUDY PROTOCOL}

After we had measured blood pressure and had obtained a standard 12 lead electrocardiogram, we injected adenosine triphosphate intravenously as rapidly as possible (within 5 seconds). Eight attacks in eight patients were treated with $20 \mathrm{mg}$ and three attacks in two patients were treated with $10 \mathrm{mg}$. Lead II or CM5 electrocardiograms were continuously recorded from just before the injection to one minute after the end of tachycardia or until two minutes after the end of adenosine triphosphate injection, and the electrocardiogram was then monitored for the next five minutes. We noted the interval between adenosine triphosphate injection and the end of tachycardia, the pause at termination, the pattern of interruption, side effects, and blood pressure three minutes after termination.

\section{Results}

Five episodes of tachycardia were treated with adenosine triphosphate within two hours and six episodes were treated between three and five hours after the beginning of the episode. Systolic blood pressure before treatment varied from $7 \cdot 71$ to $15.96 \mathrm{kPa}(58$ to $120 \mathrm{~mm} \mathrm{Hg}$ ). In three cases (four episodes) diastolic blood pressure was too low to measure with a sphygmomanometer.

The Figure shows a typical response on the electrocardiogram (lead CM5) to $20 \mathrm{mg}$ of adenosine triphosphate (case 10). The heart rate during tachycardia was 160 beats/minute. The tachycardia ended 6.2 seconds after injection of the nucleotide, and this was followed by sinus rhythm with wide QRS complex and pronounced atrioventricular block. Regular sinus rhythm was restored 14.4 seconds after the end of tachycardia, after an intervening period of atrioventricular dissociation. The patient complained of mild nausea which disappeared within 10 seconds.
All patients responded well to adenosine triphosphate. In the patient with sick sinus syndrome, however, a second episode of supraventricular of tachycardia started five minutes after the end of the $\dot{\omega}$ first episode. On two separate occasions a patient i with Wolff-Parkinson-White syndrome was successfully treated with adenosine triphosphate. Table 을 2 summarises the effects of the nucleotide on the electrocardiograms obtained during the 11 episodes. Tachycardia ended within 15 seconds (mean $10.7(3.4)$ ) of the start of the injection of adenosine triphosphate. The first QRS complex appeared within four seconds of the end of tachycardia in 10 episodes; the remaining episode was followed by a pause lasting for approximately six seconds. The first QRS complex originated from the sinus node after six episodes, from the atrioventricular junction after four episodes, and from the ventricle after one episode. The longest $R-R$ interval occurred between the first and the second heart beat or between the second and the third heart beat in six episodes, and after two episodes the longest $R-R$ interval occurred immediately after the end of tachycardia. Sinus arrest or pronounced sinus bradycardia and atrioventricular block with junctional escape beats were common features at the end of tachycardia. Regular sinus rhythm was restored within 18 seconds of the end of tachycardia. No ventricular arrhythmias were precipitated. Blood pressure measured three minutes after the end of tachycardia was significantly higher than during tachycardia.

\section{SIDE EFFECTS}

Eight patients reported side effects, but these resolved within 20 seconds and required no action.

\section{Discussion}

All 11 episodes of paroxysmal supraventricular tachycardia in 10 patients responded successfully to treatment with intravenous injection of adenosine triphosphate. Digitalis, beta blockers, and cardioversion have all been used for the short term treatment of paroxysmal supraventricular tachycardia, but intravenous verapamil is the current drug of 


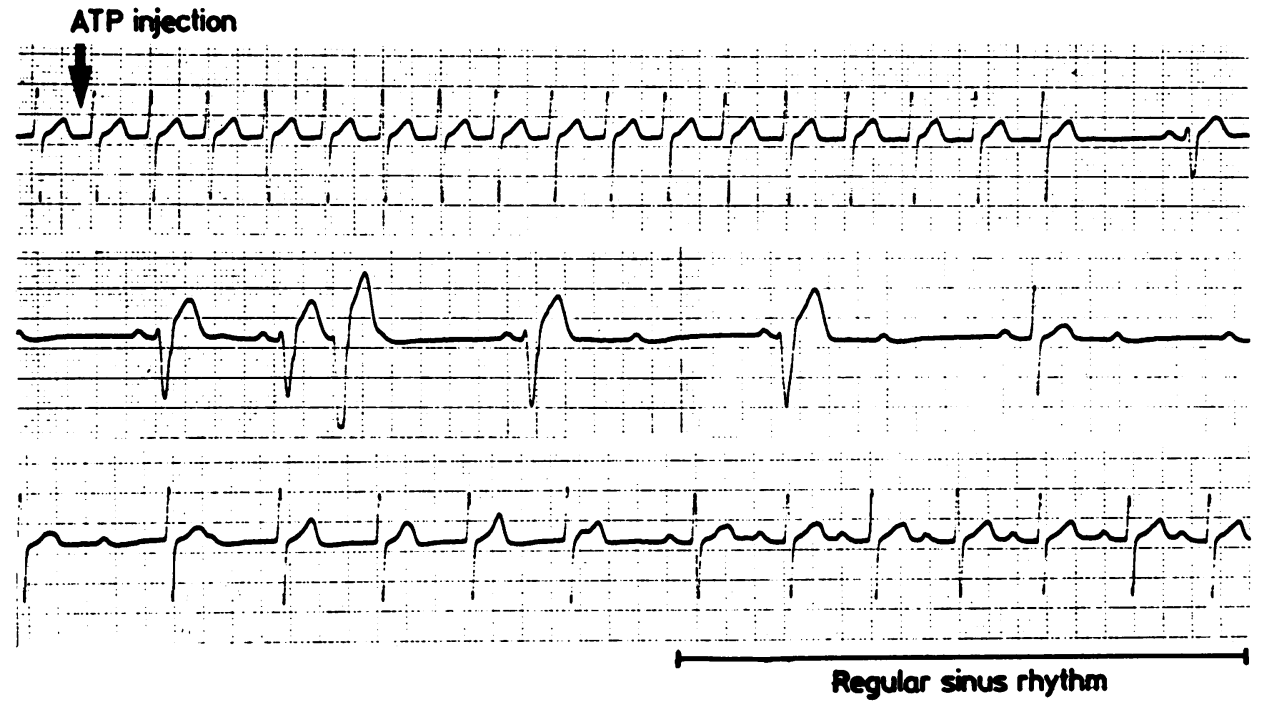

Fig Electrocardiogram from lead CM5 in case 10. Three continuous sections of the record are shown. Paroxysmal supraventricular tachycardia ended 6.2 seconds after injection of adenosine triphosphate (20 mg), and 14.4 seconds later regular sinus rhythm (100 beats/min) was restored.

choice. Verapamil is reported to be successful in most patients, ${ }^{1213}$ but it can cause hypotension or bradycardia and aggravate heart failure, especially in patients with myocardial disease ${ }^{14}$ or in those who have been treated with beta blockers. ${ }^{15}$ The half life of intravenous verapamil has been estimated to be 18-45 minutes in the initial rapid phase ( $\alpha$ phase) and 3-6 hours in the later slow period ( $\beta$ phase), ${ }^{16} 17$ and persistence of the active drug in the plasma may complicate the management of patients with side effects. A comparative study of adenosine and adenosine triphosphate in the dog showed that the nucleotide produced direct negative dromotropic and chronotropic effects on atrioventricular conduction and on atrioventricular junctional rhythm respectively. ${ }^{3}$ DiMarco et al also reported a remarkable effect of adenosine for short term treatment of supraventricular tachycardia whenever re-entry through the atrioventricular node is involved. ${ }^{18}$ These effects strongly suggest that adenosine triphosphate may be effective in terminating acute episodes of supraventricular tachycardia that affect the atrioventricular node via the re-entry pathway. Previous reports had suggested that the actions of adenosine triphosphate on tachycardia are due to adenosine produced by hydrolysis of the nucleotide. ${ }^{36}$

Table 2 Timing of electrocardiographic events after injection of adenosine triphosphate

\begin{tabular}{|c|c|c|c|c|c|c|}
\hline Case No & $A T P$ dose (mg) & I to end time (s) & End to P time (s) & End to $R$ time (s) & $\begin{array}{l}\text { Longest } R-R \\
\text { interval }(\mathrm{s})^{\star}\end{array}$ & $\begin{array}{l}\text { End to sinus time } \\
(\mathrm{s})\end{array}$ \\
\hline $\begin{array}{l}1 \\
2 \\
3 \mathrm{a} \\
3 \mathrm{~b} \\
4 \\
5 \\
6 \\
7 \\
8 \\
9 \\
10 \\
\text { Mean } \\
\text { SD }\end{array}$ & $\begin{array}{l}10 \\
10 \\
10 \\
20 \\
20 \\
20 \\
20 \\
20 \\
20 \\
20 \\
20\end{array}$ & $\begin{array}{r}10.8 \\
12.0 \\
8.4 \\
10.0 \\
15.0 \\
12.0 \\
8.0 \\
10.0 \\
7.4 \\
14.4 \\
6.2 \\
10.7 \\
3.4\end{array}$ & $\begin{array}{r}1.8 \\
2.6 \\
1.0 \\
8.5 \\
3.0 \\
6.0 \\
2.0 \\
1.7 \\
3.6 \\
10.0 \\
0.8 \\
3.7 \\
3.1\end{array}$ & $\begin{array}{l}2 \cdot 1 \\
2 \cdot 8 \\
1 \cdot 2 \\
1 \cdot 3 \\
3 \cdot 2 \\
1 \cdot 8 \\
2 \cdot 5 \\
0.5 \\
2 \cdot 1 \\
6 \cdot 0 \\
1 \cdot 0 \\
2 \cdot 2 \\
1.5\end{array}$ & $\begin{array}{r}1.8 \\
3.2 \\
1.4 \\
3.2 \\
3.2 \\
2.8 \\
6.0 \\
2.3 \\
2.0 \\
10.0 \\
1.7 \\
3.4 \\
2.5\end{array}$ & $\begin{array}{r}7 \cdot 1 \\
11 \cdot 2 \\
2 \cdot 1 \\
10 \cdot 0 \\
14 \cdot 0 \\
6 \cdot 2 \\
10 \cdot 4 \\
11 \cdot 0 \\
8 \cdot 5 \\
15 \cdot 0 \\
14 \cdot 4 \\
10 \cdot 0 \\
3.9\end{array}$ \\
\hline
\end{tabular}

ATP, adenosine triphosphate; I to end time, interval from injection of adenosine triphosphate to end of tachycardia; end to P time, time from end of tachycardia to the first $P$ wave after termination of tachycardia; end to $R$ time, time from end of tachycardia to the first $Q R S$ complex after end of tachycardia; end to sinus time, time from end of tachycardia to restoration of regular sinus rhythm; SD, standard deviation.

$\star$ Longest $R-R$ interval after end of tachycardia. 
Ronca-Testoni and Borghini have shown that adenosine triphosphate is almost completely metabolised to adenosine during a single passage across the heart, and adenosine ${ }^{19}$ is only effective for $30 \mathrm{sec}-$ onds because it is so rapidly taken up by most types of cell and deaminated to inosine which is inactive. The rapid clearance of adenosine triphosphate from plasma means that tachycardia may be safely treated by monitoring the response to a given dose over only one or two minutes, and then gradually increasing the dose until the arrhythmia stops. Repeated doses, even when these are increased, are not cumulative, and the side effects disappear within seconds. This characteristic is the main advantage of adenosine triphosphate, which did not cause harmful side effects and is unlikely to interact in an unpredictable way with other drugs or cardioversion.

We used $10 \mathrm{mg}$ or $20 \mathrm{mg}$ doses of adenosine triphosphate in this study. Greco et al used $15 \mathrm{mg}$ of adenosine triphosphate to treat episodes of tachycardia in infancy. ${ }^{20}$ In adults, Somlo, ${ }^{21}$ Komor and Garas, ${ }^{22}$ Coumel et $a l,{ }^{23}$ and Motte and his coworkers $^{24}$ have reported considerable success after single doses of $10-70 \mathrm{mg}$ of the nucleotide without harmful side effects. In the present study 10 mg of adenosine triphosphate successfully converted tachycardia to sinus rhythm in all three cases in which it was used. This result suggests that, in Japanese patients at least, doses of the nucleotide should start at $10 \mathrm{mg}$ or less with a gradual increase in dose every two or three minutes until the tachycardia is terminated.

In conclusion, adenosine triphosphate has features that indicate that it may be one of the safest and the most effective methods of treating paroxysmal supraventricular tachycardia, but more extensive trials are needed to establish this.

\section{References}

1 Belhassen B, Pelleg A. Electrophysiologic effects of adenosine triphosphate and adenosine on the mammalian heart: clinical and experimental aspects. $\mathcal{f} \mathrm{Am}$ Coll Cardiol 1984; 4: 414-24.

2 James TN. The chronotropic action of ATP and related compounds studied by direct perfusion of the sinus node. $f$ Pharmacol Exp Ther 1965; 149: 233-47.

3 Urthaler F, James TN. Effects of adenosine and ATP on AV conduction and on AV junctional rhythm. f Lab Clin Med 1972; 79: 96-105.

4 Belardinelli L, Belloni FL, Rubio R, Berne RM. Atrioventricular conduction disturbances during hypoxia. Possible role of adenosine in rabbit and guinea pig heart. Circ Res 1980; 47: 684-91.

5 Belardinelli L, Mattos EC, Berne RM. Evidence for adenosine mediation of atrioventricular block in the ischemic canine myocardium. F Clin Invest 1981; 68: 195-205.

6 DiMarco JP, Sellers TD, Berne RM, West GA, Belardinelli L. Adenosine: electrophysiologic effects and therapeutic use for terminating paroxysmal supra- ventricular tachycardia. Circulation 1983; 68: 1254-63

7 Belardinelli L, Fenton RA, West A, Linden J, Althaus: JS, Berne RM. Extracellular action of adenosine and antagonism by aminophylline on the atrioventricular conduction of isolated perfused pig and rat hearts. Circ Res 1982; 51: 569-79.

8 Belardinelli L, Isenberg G. Isolated atrial myocytes: $\frac{\bar{\Phi}}{\Phi}$ adenosine and acetylcholine increase potassium con- $\Omega$ ductance. Am F Physiol (Heart Circ Physiol) 1983; 244 H734-7.

9 Schrader J, Rubio R, Berne RM. Inhibition of slow? action potentials of guinea pig atrial muscle by ade- $\overrightarrow{-}$ nosine. A possible effect on $\mathrm{Ca}$ influx. $\mathcal{F} \mathrm{Mol} \mathrm{Cel}_{\mathrm{S}}$ Cardiol 1975; 7: 427-33.

10 Belardinelli L, Vogel S, Linden J, Berne RM. Antiadrenergic action of adenosine on ventricular myo- $\mathrm{N}$ cardium in embryonic chick hearts. $\mathcal{F} \mathrm{Mol}$ Cell Cardio $\dot{\omega}$ 1982; 14: 291-4.

11 Wolff GS, Sung RJ, Pickoff A, et al. The fast-slow form of atrioventricular nodal reentrant tachycardia in children. Am $\mathcal{F}$ Cardiol 1979; 43: 1181-8.

12 Spurrell RAJ, Krikler DM, Sowton E. Effects of verapamil on electrophysiological properties of anomalous atrioventricular connexion in Wolff-Parkinson-White syndrome. Br Heart f 1974; 36: 256-64.

13 Soler-Soler J, Sagrista-Sauleda J, Cabrera A, et al.ळ Effect of verapamil in infants with paroxysmal supra-: ventricular tachycardia. Circulation 1979; 59: 876-8.

14 Apitz J, Gaissmaier U. Zwischenfall mit todlichen Augsgang nach intravenoser injektion von Isoptin. Med Klin 1971; 66: 751-5.

15 Urthaler F, James TN. Experimental studies on the pathogenesis of asystole after verapamil in the $\operatorname{dog}$ Am 7 Cardiol 1979; 44: 651-6.

16 Schomerus M, Spiegelhalder B, Stieren B, Einchelbaum M. Physiological disposition of verapamil in man. Cardiovasc Res 1976; 10: 605-12.

17 Henry PD. Comparative pharmacology of calcium antagonists: nifedipine, verapamil and diltiazem. $A m$ SD Cardiol 1980; 46: 1047-58.

18 DiMarco JP, Sellers TD, Lerman BB, Greenberg ML, 윽 Berne RM, Belardinelli L. Diagnostic and therapeutic use of adenosine in patients with supraventricularo tachycardia. $7 \mathrm{Am}$ Coll Cardiol 1985; 6: 417-25.

19 Ronca-Testoni S, Borghini F. Degradation of perfusedo adenine compounds up to uric acid in isolated rat heart f Mol Cell Cardiol 1982; 14: 177-80.

20 Greco R, Musto B, Arienzo V, Alborino A, Garofalo S, Marsico F. Treatment of paroxysmal supraventricularer tachycardia in infancy with digitalis, adenosine $-5^{\prime} \mathrm{N}$ triphosphate, and verapamil: a comparative study요 Circulation 1982; 66: 504-8.

21 Somlo E. Adenosine triphosphate in paroxysmal tachy cardia [Letter]. Lancet 1955; i: 1125.

22 Komor K, Garas Zs. Adenosine triphosphate in paroxysmal tachycardia [Letter]. Lancet 1955; ii: 93-4. \&

23 Coumel P, Motte G, Gourgon R, Fabiato A, Scama R, Bouvrain $Y$. Les tachycardies supraventricularies pao rythme reciproque en dehors du syndrome dex Wolff-Parkinson-White. Arch Mal Coeur 1970; 63蛋 35-73.

24 Motte G, Waynberger M, Lebars A, Bouvrain Y L'adenosine triphosphorique dans les tachycardies par oxystiques. Nouv Presse Med 1972; 1: 3057-61. 